
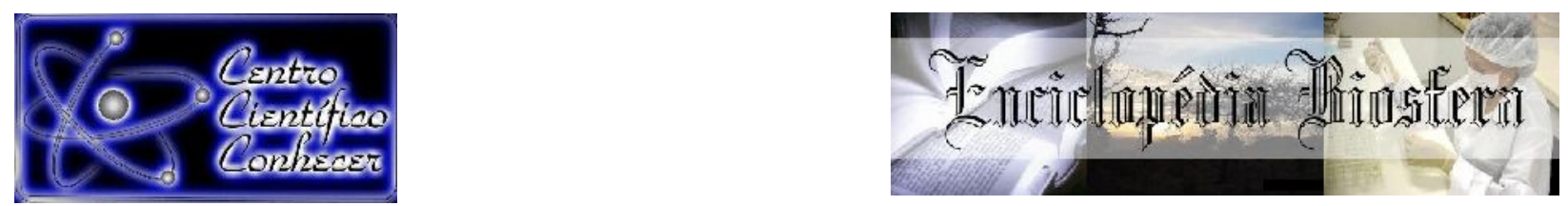

\title{
COMPOSIÇÃO FLORÍSTICA E DISTRIBUIÇÃO ESPACIAL DE PLANTAS DANINHAS EM PRÉ-SEMEADURA DE SOJA EM UBERLÂNDIA - MG
}

\footnotetext{
Reinaldo Silva Oliveira Canuto ${ }^{1}$, Débora Maria Ferreira Oliveira Canuto ${ }^{2}$

${ }^{1}$ Doutor em Agronomia (Fitotecnia) e professor do Instituto Federal de Educação, Ciência e Tecnologia do Triângulo Mineiro, Campus Uberlândia, Uberlândia, MG. Email: reinaldo@iftm.edu.br

${ }^{2}$ Doutora em Ciências e professora da Universidade Presidente Antônio Carlos, Campus Delta, Uberlândia, MG
Recebido em: 15/08/2021 - Aprovado em: 15/09/2021 - Publicado em: 30/09/2021 DOI: $10.18677 /$ EnciBio_2021C47

trabalho licenciado sob licença Creative Commons Attribution-NonCommercial-NoDerivatives 4.0 International License.
}

\section{RESUMO}

Consideradas como plantas indesejadas nos sistemas de produção de soja, as plantas daninhas causam prejuízos à produtividade de grãos em função da competição pelos recursos essenciais como água, luz, nutrientes e espaço. Devido aos danos que podem causar, as plantas infestantes devem ser criteriosamente identificadas e quantificadas para a definição das estratégias que constituirão o manejo integrado de plantas daninhas. Portanto, este trabalho apresentou como objetivo o levantamento da composição florística e da distribuição espacial de plantas daninhas em área experimental do IFTM Campus Uberlândia (Uberlândia$M G$ ), especificamente em pré-semeadura da cultura da soja. A amostragem das plantas daninhas foi realizada por meio do método do quadrado inventário, com o lançamento do quadrado $(0,5 \mathrm{~m} \times 0,5 \mathrm{~m})$ em 20 pontos aleatórios da área experimental. Em cada ponto amostral, as plantas daninhas foram identificadas e quantificadas para a posterior análise da composição florística e da fitossociologia. As características avaliadas foram: frequência, densidade e abundância (absolutas e relativas) e índice de valor de importância. As famílias com maior representatividade no local foram Poaceae e Amaranthaceae, com 3 espécies cada. Entretanto, a família Cyperaceae, por apresentar a espécie Cyperus rotundus com maior índice de valor de importância (IVI), se destacou na área experimental. Esta espécie, juntamente com outras duas espécies da família Poaceae (Digitaria horizontalis e Eleusine indica) apresentaram os maiores valores dos índices fitossociológicos, inclusive do IVI, e devem ser priorizadas quanto à definição do programa de manejo integrado de plantas daninhas em pré-semeadura de soja.

PALAVRAS-CHAVE: Cyperus rotundus, Digitaria horizontalis, Eleusine indica. 


\title{
FLORISTIC COMPOSITION AND SPATIAL DISTRIBUTION OF WEEDS IN PRE- SOWING SOYBEAN IN UBERLÂNDIA - MG
}

\begin{abstract}
Considered as unwanted plants in soybean production systems, weeds cause damage to grain yield due to competition for essential resources such as water, light, nutrients, and space. Due to the damage, they can cause, weeds must be carefully identified and quantified to define the strategies that will constitute the integrated weed management. Therefore, this work aimed to survey the floristic composition and spatial distribution of weeds in an experimental area of the IFTM Campus Uberlândia (Uberlândia-MG), specifically in pre-sowing soybean crop. Weed sampling was carried out using the square inventory method, with the launching of the square $(0.5 \mathrm{~m} \times 0.5 \mathrm{~m})$ at 20 random points in the experimental area. At each sampling point, weeds were identified and quantified for further analysis of floristic composition and phytosociology. The characteristics evaluated were frequency, density and abundance (absolute and relative) and importance value index. The most representative families in the place were Poaceae and Amaranthaceae, with 3 species each. However, the Cyperaceae family, for presenting the species Cyperus rotundus with the highest importance value index (IVI), stood out in the experimental area. This species, along with two other species of the Poaceae family (Digitaria horizontalis and Eleusine indica) had the highest values of phytosociological indices, including the IVI, and should be prioritized in terms of the definition of the integrated weed management program in pre-sowing of soybeans.
\end{abstract}

KEYWORDS: Cyperus rotundus, Digitaria horizontalis, Eleusine indica.

\section{INTRODUÇÃO}

Existem várias definições de "plantas daninhas", porém, Pitelli (1987) as definiu como plantas que emergem nos agroecossistemas causando interferências à produtividade das plantas cultivadas. Em cultivo de soja, por exemplo, a ausência de controle destas plantas infestantes no período crítico de prevenção da interferência (18 aos 31 dias após a emergência da soja) reduziu significativamente a produtividade de grãos (VITORINO et al., 2017). No atual cenário internacional de destaque em produção e exportação de soja (CONAB, 2021), os agricultores brasileiros necessitam planejar adequadamente as ações de manejo da cultura para a obtenção de elevadas produtividades. Entre estas ações, a definição correta das estratégias de controle das espécies de plantas daninhas torna-se fundamental.

O grau de interferência das plantas daninhas sobre as plantas cultivadas é variável em função de fatores inerentes à cultura, ao ambiente e ao período de convivência. Por ocuparem praticamente o mesmo local onde uma determinada cultura será manejada, as plantas daninhas aproveitam, também, os mesmos recursos essenciais ao seu desenvolvimento, como água, luz, nutrientes e espaço. A competição por estes recursos, nem sempre disponíveis em quantidades satisfatórias para todas as plantas presentes no mesmo espaço, pode ser muito intensa (PITELLI, 1985). Geralmente, as plantas daninhas apresentam maior capacidade competitiva em relação às plantas cultivadas, gerando prejuízos que podem ser maiores do que os ocasionados por outros problemas fitossanitários como as pragas e doenças (VASCONCELOS et al., 2012).

$\mathrm{Na}$ agricultura, a dinâmica populacional das plantas daninhas pode ser influenciada pelo manejo do solo, pelo manejo cultural e pelo sistema de colheita das plantas cultivadas. Desta forma, é necessária a compreensão do nível de influência de cada um destes fatores na variação espacial e temporal da ocorrência ENCICLOPÉDIA BIOSFERA, Centro Científico Conhecer - Jandaia-GO, v. 18 n.37; p. 655 2021 
de plantas infestantes. Dependendo do manejo adotado, se não realizado de forma adequada, poderá contribuir para o aumento do banco de sementes no solo. Ainda no perfil deste solo mal manejado, além ao aumento quantitativo do número de espécies de plantas daninhas que podem emergir e competir com a cultura, há também o aumento qualitativo, ou seja, o aumento da diversidade de plantas daninhas competidoras pelos recursos essenciais à sobrevivência das espécies. Com o monitoramento constante da comunidade infestante, é possível determinar as espécies dominantes e adotar ações no sentido de controlá-las (FORTE et al., 2018; SILVA et al., 2018; PINTO et al., 2021).

O levantamento populacional de plantas daninhas, também denominado de levantamento fitossociológico ou análise de composição florística, permite conhecer as espécies mais importantes a serem manejadas em qualquer sistema de produção agrícola (SILVA et al., 2017). O manejo integrado de plantas daninhas somente pode ser realizado de forma satisfatória se houver o conhecimento detalhado da comunidade infestante. Assim, será possível definir as melhores estratégias para cada situação agrícola, contribuindo para a redução nos custos da produção e impacto ao meio ambiente (COSTA et al., 2019).

Diante do exposto acima, o presente trabalho apresentou como objetivo a realização do levantamento da composição florística e da distribuição espacial das espécies de plantas daninhas em área experimental da Fazenda Sobradinho, do IFTM Campus Uberlândia, em Uberlândia, Minas Gerais. O local tem sido destinado às pesquisas agronômicas com a cultura da soja, milho e trigo, mas as plantas daninhas foram avaliadas durante o pousio, em pré-semeadura da cultura da soja. Este levantamento foi uma ação importante para o conhecimento da comunidade infestante e para a adoção de estratégias mais específicas para o controle das plantas daninhas predominantes.

\section{MATERIAL E MÉTODOS}

O levantamento das espécies de plantas daninhas para a análise de composição florística e distribuição espacial de plantas daninhas foi realizado em área experimental do Instituto Federal do Triângulo Mineiro Campus Uberlândia, a qual está localizada nas coordenadas geográficas de 18 $46^{\prime} 07^{\prime \prime}$ de latitude Sul e 48 17'40" de longitude oeste, com altitude de $650 \mathrm{~m}$ e classificação climática Aw, segundo Köppen-Geiger, com temperatura e precipitação média anual igual à $22,3^{\circ} \mathrm{C}$ e $1.342 \mathrm{~mm}$ (PEEL et al., 2007). A área total o levantamento apresentou 3.919,18 $\mathrm{m}^{2}$ e o solo foi classificado como Latossolo Vermelho distrófico.

O levantamento das espécies de plantas daninhas foi realizado com auxílio de um quadrado inventário $(0,5 \mathrm{~m} \times 0,5 \mathrm{~m})$, construído com tubos de PVC. Foram realizados 20 lançamentos do quadrado inventário em pontos aleatórios da área amostrada. A área tem sido utilizada para experimentos realizados com as culturas do trigo, milho e soja. A última cultura cultivada no local foi o trigo, com colheita realizada na segunda quinzena de agosto. Porém, no momento da amostragem das espécies de plantas infestantes, na última semana de outubro, o local estava em pousio e havia uma programação para a realização de um projeto com a cultura da soja.

Visando manejar corretamente as daninhas com herbicidas pré e pósemergentes seletivos à cultura, o conhecimento das espécies e da distribuição destas na área experimental tem sido uma prática fundamental. Além da quantificação das espécies e do total de indivíduos por área amostrada ainda foram 
calculados os parâmetros fitossociológicos propostos por Mueller-Dombois e Ellenberg (1974):

Frequência:

$\mathrm{F}=$ (Número de parcelas que contém a espécie) / (Total de parcelas)

Densidade:

$\mathrm{D}=$ (Total de indivíduos por espécie) / (Total de parcelas)

Abundância:

$\mathrm{A}=$ (Total de indivíduos por espécie) / (Total de parcelas contendo a espécie)

Freqüência relativa:

$\mathrm{Fr}=($ Frequência da espécie $\mathrm{X} 100)$ / (Frequência de todas as espécies)

Densidade relativa:

$\mathrm{Dr}=$ (Densidade da espécie $\mathrm{X} 100) /($ Densidade de todas as espécies)

Abundância relativa:

$\mathrm{Ar}=$ (Abundância da espécie X 100) / (Abundância de todas as espécies)

Índice de valor de importância:

$\mathrm{IVI}=\mathrm{Fr}+\mathrm{Dr}+\mathrm{Ar}$

\section{RESULTADOS E DISCUSSÃO}

A comunidade infestante do local foi composta por 15 espécies de plantas daninhas, pertencentes à 11 famílias. As principais famílias encontradas foram Poaceae e Amaranthaceae, representando, cada uma, cerca de $20 \%$ do total de espécies identificadas na área (Quadro 1).

QUADRO 1. Espécies de plantas daninhas, agrupadas por família, em função do levantamento realizado em área experimental da Fazenda Sobradinho, do IFTM Campus Uberlândia, em Uberlândia, Minas Gerais.

\begin{tabular}{lll}
\hline Família & Nome Comum & Nome científico \\
\hline \multirow{2}{*}{ Amaranthaceae } & apaga-fogo & Alternanthera tenella \\
& caruru-de-espinho & Amaranthus spinosus \\
& caruru-de-mancha & Amaranthus viridis \\
\hline Asteraceae & agriãozinho-do-campo & Synedrellopsis grisebachii \\
\hline Commelinaceae & trapoeraba & Commelina benghalensis \\
\hline Convolvulaceae & corda-de-viola & Ipomoea triloba \\
\hline Cyperaceae & tiririca & Cyperus rotundus \\
\hline Fabaceae & carrapicho-beiço-de-boi & Desmodium tortuosum \\
\hline Malvaceae & guanxuma & Sida rhombifolia \\
\hline Nyctaginaceae & erva-tostão & Boheravia diffusa \\
\hline & capim-colchão & Digitaria horizontalis \\
Poaceae & capim-amargoso & Digitaria insularis \\
& capim-pé-de-galinha & Eleusine indica \\
\hline Portulacaceae & beldroega & Portulaca oleraceae \\
\hline Solanaceae & joá-de-capote & Nicandra physaloides \\
\hline
\end{tabular}


As duas espécies de plantas daninhas que apresentaram maiores frequências, densidades e abundâncias (absolutas e relativas) na área experimental da Fazenda Sobradinho foram: Cyperus rotundus (tiririca) e Digitaria horizontalis (capim-colchão) (Tabela 1).

TABELA 1. Número em presença em quadrados (NQ), número de indivíduos (NI), frequência $(F)$, densidade $(D)$, abundância $(A)$, frequência relativa $(F r)$, densidade relativa (Dr), abundância relativa (Ar) e índice de valor de importância (IVI) das espécies de plantas daninhas em área experimental da Fazenda Sobradinho, do IFTM Campus Uberlândia, em Uberlândia, Minas Gerais.

\begin{tabular}{lcccccccc}
\hline Espécies & NI & NQ & F & D & A & Fr & Dr & Ar \\
\hline Alternanthera tenella & 1 & 1 & 0,05 & 0,05 & 1,00 & 1,03 & 0,14 & 1,70 \\
Amaranthus spinosus & 10 & 6 & 0,30 & 0,50 & 1,67 & 6,19 & 1,38 & 2,83 \\
Amaranthus viridis & 32 & 9 & 0,45 & 1,60 & 3,56 & 9,28 & 4,41 & 6,03 \\
S. grisebachii & 1 & 1 & 0,05 & 0,05 & 1,00 & 1,03 & 0,14 & 1,70 \\
C. benghalensis & 9 & 7 & 0,35 & 0,45 & 1,29 & 7,22 & 1,24 & 2,18 \\
Ipomoea triloba & 5 & 4 & 0,20 & 0,25 & 1,25 & 4,12 & 0,69 & 2,12 \\
Cyperus rotundus & 396 & 20 & 1,00 & 19,80 & 19,80 & 20,62 & 54,62 & 33,57 \\
D. tortuosum & 3 & 1 & 0,05 & 0,15 & 3,00 & 1,03 & 0,41 & 5,09 \\
Sida rhombifolia & 1 & 1 & 0,05 & 0,05 & 1,00 & 1,03 & 0,14 & 1,70 \\
Boheravia difusa & 1 & 1 & 0,05 & 0,05 & 1,00 & 1,03 & 0,14 & 1,70 \\
Digitaria horizontalis & 142 & 16 & 0,80 & 7,10 & 8,88 & 16,49 & 19,59 & 15,05 \\
Digitaria insularis & 13 & 5 & 0,25 & 0,65 & 2,60 & 5,15 & 1,79 & 4,41 \\
Eleusine indica & 70 & 10 & 0,50 & 3,50 & 7,00 & 10,31 & 9,66 & 11,87 \\
Portulaca oleraceae & 27 & 11 & 0,55 & 1,35 & 2,45 & 11,34 & 3,72 & 4,16 \\
Nicandra physaloides & 14 & 4 & 0,20 & 0,70 & 3,50 & 4,12 & 1,93 & 5,93 \\
\hline TOTAL & 725 & 20 & 5 & 36,25 & 58,99 & 100,0 & 100,0 & 100,0 \\
\hline
\end{tabular}

Embora as plantas daninhas de folhas largas (dicotiledôneas) representaram a maioria da comunidade infestante na área experimental, com quase $70 \%$ do total das espécies identificadas, o planejamento de ações para realizar o manejo integrado das plantas infestantes deve considerar a aplicação de herbicidas que tenham efeito sobre as duas espécies de folha estreita (monocotiledôneas) que, apesar de serem minoria no quantitativo de espécies do levantamento, foram encontradas com maior índice de valor de importância (IVI cyperus rotundus $=108,8 \%$; IVI Digitaria horizontalis $=51,1 \%$ ) (Figura 1). Para o controle destas espécies de plantas daninhas, herbicidas pré-emergentes podem ser utilizados após o preparo do solo com gradagem, antes da semeadura da soja. Herbicidas como clomazone, smetolachlor e sulfentrazone podem ser empregados nesta situação. Em pósemergência, as demais espécies de plantas daninhas que emergirem podem ser manejadas com glifosato, considerando 0 cultivo de soja tolerante glifosato (NONEMACHER et al., 2017; NUNES et al., 2018). 
FIGURA 1. Levantamento fitossociológico de plantas daninhas em área experimental da Fazenda Sobradinho, do IFTM Campus Uberlândia, em Uberlândia, Minas Gerais. Fr: frequência relativa (\%); Dr: densidade relativa (\%); Ar: abundância relativa (\%); IVI: índice de valor de importância (\%).

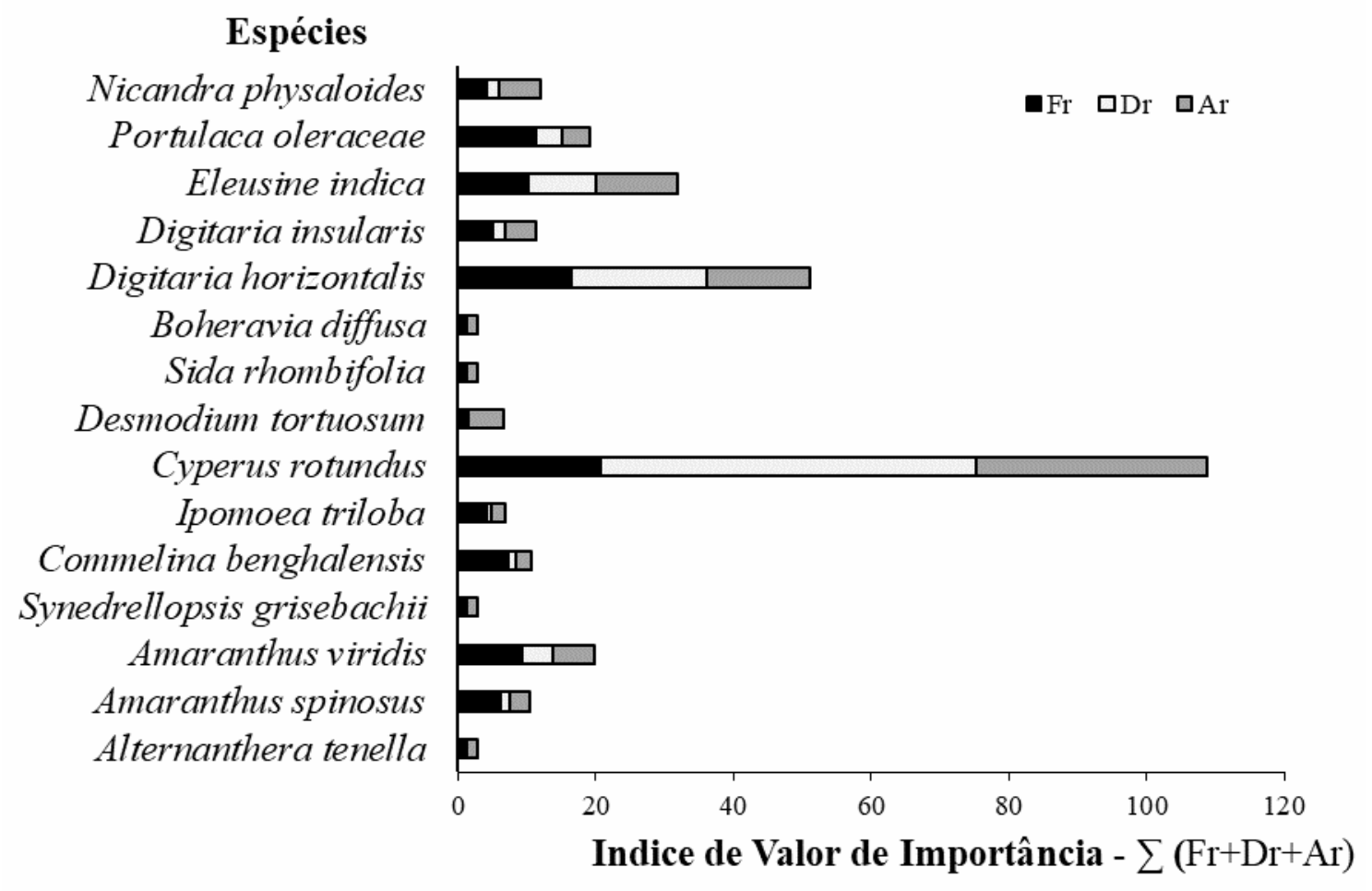

Fonte: Autores (2021).

Cyperus rotundus foi à espécie de planta daninha de maior importância no levantamento realizado na área experimental. As práticas mecânicas adotadas para a preparação do solo ao longo dos anos agrícolas para subsidiar a condução das pesquisas científicas com as culturas do feijão, da soja, do milho e do trigo têm favorecido a propagação desta planta infestante. A tiririca se multiplica por sementes, mas a principal forma de propagação em ambientes manejados com aração e gradagem é por meio dos tubérculos, os quais são segmentados e originam novas plantas no local contribuindo para o aumento da densidade, ou seja, do número de plantas emergidas por metro quadrado. Como estes tubérculos podem permanecer dormentes no solo por longos períodos (KHATOUNIAN et al., 2018) e emergir de profundidades de $50 \mathrm{~cm}$ do solo (ROOZKHOSH et al., 2017), as perdas da produção agrícola podem ser expressivas.

Outro fator associado à interferência da tiririca no desenvolvimento da cultura de soja é a alelopatia. Substâncias liberadas por esta espécie de planta daninha têm o potencial de reduzir a porcentagem de germinação de sementes e a massa seca de plântulas de soja (BEGOSSO; WAURECK, 2019). Assim, como este fator é prejudicial ao desenvolvimento inicial da cultura, são necessários o monitoramento e o controle eficiente de $C$. rotundus.

Ao realizar o levantamento fitossociológico de plantas daninhas em cultivos de amoreira, framboesa, macieira e marmeleiro, em área experimental do setor de Fruticultura da Universidade Federal de Lavras, a espécie C. rotundus apresentou maior índice de valor de importância. Além dos fatores citados anteriormente, que explicam a agressividade da planta daninha, os pesquisadores também atribuíram o ENCICLOPÉDIA BIOSFERA, Centro Científico Conhecer - Jandaia-GO, v. 18 n.37; p. 659 2021 
alto IVI às condições ambientais, temperatura e alta luminosidade que favoreceram o desenvolvimento da tiririca nos ambientes de produção estudados (ARAÚJO et al., 2020).

No presente trabalho, a família Poaceae apresentou maior representatividade no levantamento. Esta família tem sido encontrada com muita frequência nos trabalhos de monitoramento das espécies de plantas daninhas. Em áreas destinadas à produção de grãos de soja em Luís Eduardo Magalhães, na Bahia, por exemplo, foi verificada a predominância das espécies da família Poaceae, com 8 representantes (CAETANO et al., 2018). Semelhantemente, Adegas et al. (2010), ao realizarem o levantamento de plantas daninhas em cultivo de girassol no Cerrado goiano e mato-grossense e na região dos pampas localizada no Rio Grande do Sul, também identificaram a presença majoritária de espécies de infestantes pertencentes à Família Poaceae. Isso também foi relatado em outras culturas agrícolas como cana-de-açúcar (OLIVEIRA; FREITAS, 2008), mandioca (CARDOSO et al., 2013; SOARES et al., 2015) e feijão (SILVA et al., 2017).

Por ser de ampla ocorrência nos levantamentos de plantas daninhas realizados em diferentes sistemas de produção agrícola no Brasil, a família Poaceae apresenta notável importância quanto à definição de programas de manejo integrado. Embora seja possível adotar ações relacionadas ao controle cultural, as plantas daninhas de folhas estreitas são frequentemente controladas com herbicidas. Entretanto, devido ao uso não racional dos herbicidas, algumas espécies de monocotiledôneas daninhas têm sido selecionadas quanto à manifestação da resistência a alguns grupos químicos de herbicidas. A espécie Eleusine indica (péde-galinha), encontrada em diferentes regiões agrícolas do mundo, inclusive na área experimental do presente trabalho, tem registros de casos de resistência a partir do ano de 2003 em cultivos de soja, milho, trigo, feijão e algodão no Brasil e em áreas de soja, milho e pousio na Argentina. Desde 2003 até o presente momento, foram registrados 37 casos no mundo, sendo três no Brasil (em 2003, 2016 e 2017) em relação aos herbicidas cyhalofop, fenoxaprop, sethoxydim, glyphosate e haloxyfop (VÁZQUEZ-GARCíA et al., 2021; WEEDSCIENCE, 2021).

\section{CONCLUSÃO}

Com o levantamento fitossociológico de plantas daninhas na área experimental da Fazenda Sobradinho do IFTM Campus Uberlândia, foi possível observar que as espécies de plantas daninhas predominantes foram Cyperus rotundus (tiririca), Digitaria horizontalis (capim-colchão) e Eleusine indica (capim-péde-galinha). Estas devem ser priorizadas no planejamento de manejo integrado de plantas daninhas da área em pré-semeadura da cultura de soja.

\section{REFERÊNCIAS}

ARAÚJO, H. H. R.; SOUZA, F.B.M.; PIO, R.; FREIRE, A.I.; PEREIRA, A.M.; et al. Levantamento fitossociológico das plantas daninhas em diferentes frutíferas de clima temperado no município de Lavras-MG. Research, Society and Development, v. 9, n. 8., p. 1-21, 2020. Disponível em: <http://dx.doi.org/10.33448/rsd-v9i8.6553>. DOI: $10.33448 /$ rsd-v9i8.6553

BEGOSSO, G. J.; WAURECK, A. Influência de extratos aquosos de Lolium multiflorum L. e Cyperus rotundus em sementes de soja. Scientia Rural, v. 19, n. 1, p. 2019. 1-22, Disponível em: < 
http://www.cescage.com.br/revistas/index.php/ScientiaRural/article/view/144>.

Acesso em 10 de agosto de 2021.

CARDOSO A. D.; VIANA, A. E. S., BARBOSA, R. P.; TEIXEIRA, P. R. G.; CARDOSO JÚNIOR, N. D. S. C.; FOGAÇA, J. J. N. L. Levantamento fitossociológico de plantas daninhas na cultura da mandioca em Vitória da Conquista, Bahia. Bioscience Journal, v. 29, p. 1130-1140, 2013. Disponível em: < http://200.19.146.79/index.php/biosciencejournal/article/view/22127>. Acesso em 11 de agosto de 2021.

CONAB. Companhia Nacional de Abastecimento. Acompanhamento da safra brasileira de grãos. Brasília: Distrito Federal, v. 8, n. 10, safra 2020/21, décimo levantamento, julho, 2021. Disponível em: <https://www.conab.gov.br/infoagro/safras/graos>. Acesso em 05 de agosto de 2021.

COSTA, R. N.; SILVA, D.M.R.; ROCHA, A.O; LIMA, A.N.S.; SANTOS, J.C.C.; et al. Levantamento fitossociológico de plantas daninhas em área de produção de mamão. Revista Técnico-Científica, v. 21, n. 3, p. 183-193, 2019. Disponível em: <http://dx.doi.org/10.30945/rcr-v21i3.2790>. DOl: 10.30945/rcr-v21i3.2790

FORTE, C. T.; GALONA,N.; BEUTLERF, W.; REICHERT JUNIOR, A.D.; MENEGARTG.F; et al. Cultivation systems, vegetable soil covers and their influence on the phytosociology of weeds. Planta Daninha, v. 36, 2018. Disponível em: <http://dx.doi.org/10.1590/S0100-83582018360100099>. DOI: $10.1590 / S 0100-$ 83582018360100099

KHATOUNIAN, C. A.; OLIVEIRA, D.A.M.; FERREIRA, T.M.; DUPRE, M.; MERIANNE, H.; Distribuição dos tubérculos de tiririca (Cyperus rotundus L.) no perfil do solo e suas implicações para a conversão para a agricultura orgânica de hortas urbanas. Scientia Plena, v. 14, n. 9, p. 1-6, 2018. Disponível em: <http://dx.doi.org/10.14808/sci.plena.2018.090201>. DOI: 10.14808/sci.plena.2018.090201

MUELLER-DOMBOIS, D.; ELLENBERG, H. Aims and methods of vegetation ecology. New York: John Wiley and Sons, 1974. 547 p.

NONEMACHER, F.; GALON, L.; SATIN, C. O.; FORTE, C. T.; FIABANE, R. B.; et al.,; Herbicide association applied to control weeds in glyphosate-resistant soybean. Revista Brasileira de Herbicidas, v. 16, n. 2, p. 152-162, 2017. <http://dx.doi.org/10.7824/rbh.v16i2.529>. DOl: 10.7824/rbh.v16i2.529

NUNES, A. L.; LORENSET, J.; GUBIANI, J. E.; SANTOS, F. M. A multy-year study reveals the importance of residual herbicides on weed control in glyphosate-resistant soybean. Planta Daninha, v. 36, p. 1-10, 2018. <http://dx.doi.org/10.1590/S010083582018360100039>. DOI: 10.1590/S0100-83582018360100039

OLIVEIRA, A. R.; FREITAS, S. P. Levantamento fitossociológico de plantas daninhas em áreas de produção de cana-de-açúcar. Planta Daninha, v. 26, n. 1, p. 33-46, 2008. Disponível em: <http://dx.doi.org/10.1590/S010083582008000100004>. DOI: 10.1590/S0100-83582008000100004 
PEEL, M.C., FINLAYSON, B.L. AND MCMAHON, T.A. Updated World Map of the Köppen-Geiger Climate Classification. Hydrology and Earth System Sciences, v. 4, n. 2, p. 1633-1644, 2007. Disponível em: <http://dx.doi.org/10.5194/hess-11-16332007>. DOI: $10.5194 /$ hess-11-1633-2007

PINTO, P. H. G.; RODRIGUES, C. M. S.; LIMA, S. F.; ALVAREZ, R. C. F.; OLIVEIRA, I. C.; et al.; Coberturas vegetais na entressafra de culturas afetando o banco de sementes de plantas daninhas. Research, Society and Development, v. 10, n. 6, p. 1-10, 2021. Disponível em: <http://dx.doi.org/10.33448/rsd-v10i6.16057>. DOI: $10.33448 /$ rsd-v10i6.16057

PITELLI, R. A. Competição e controle das plantas daninhas em áreas agrícolas. Série Técnica IPEF, v. 4., n. 12, p. 1-24, 1987. Disponível em: < http://bibliotecaflorestal.ufv.br/bitstream/handle/123456789/6867/ipef-serie-tecnica1987-v-4-n-12-p-1-24.pdf?sequence=1\&isAllowed=y>. Acesso em 12 de agosto de 2021.

PITELLI, R. A. Interferência de plantas daninhas em culturas agrícolas. Informe Agropecuário, v. 11, n. 129, p. 16-27, 1985.

ROOZKHOSH, M.; ESLAMI, S. V.; AL-AHMADI, M. J. Effect of plastic mulch and burial depth on purple nutsedge (Cyperus rotundus) emergence and growth. Archives of Agronomy and Soil Science, v. 63, n. 10, p. 1454-1464, 2017. Disponível em: <http://dx.doi.org/10.1080/03650340.2017.1280782>. DOI: 10.1080/03650340.2017.1280782

SILVA, D.M.R.; SANTOS, J.C.C.; SILVA, C.H.; SANTOS, S.A.; COSTA, R.N. Levantamento fitossociológico: interferência de plantas espontâneas associadas ao cultivo de feijão carioca. Revista Agrotecnologia, v.8, n.2, p.37-43, 2017. Disponível em: <http://dx.doi.org/ 10.12971/2179-5959/agrotecnologia.v8n2p37-43>. DOI: 10.12971/2179-5959/agrotecnologia.v8n2p37-43

SILVA, J.; CUNHA, J. L. X. L.; OLIVEIRA, F. S.; SILVA, R. G. S.; GOMES, C. B.; et al.,; Composição do banco de sementes em diferentes profundidades de uma área cultivada com capim Aruana. Revista Agrarian, v. 11, n. 40, 140-149, 2018. Disponível em: <http://dx.doi.org/ 10.30612/agrarian.v11i40.5274>. DOI: 10.30612/agrarian.v11i40.5274

SOARES, M.R.S.; SÃO JOSÉ, A.R.; ARAUJO NETO, A.C.; LIMA, R.S.; MOREIRA, E.S.; PRADO, T.R. Phytosociological survey of weed in cassava cultivation in Southwestern Bahia, Brazil. African Journal of Agricultural Research, v.10, p.2120-2129, 2015. Disponível em: <http://dx.doi.org/10.5897/AJAR2015.9581>. DOI:10.5897/AJAR2015.9581

VASCONCELOS, M. C. C.; SILVA, A. F. A.; LIMA, R. S. Interferência de plantas daninhas sobre plantas cultivadas. Agropecuária Científica no Semiárido, v. 8, n. 1, p. 1-6, 2012. Disponível em: <http://dx.doi.org/10.30969/acsa.v8i1.159>. DOI: 10.30969/acsa.v8i1.159 
VÁZQUEZ-GARCÍA, J. G.; CRUZ, R. A.; ROJANO-DELGADO, A. M.; PALMABAUTISTA, C.; VASCONCELOS, J. M. P.; PRADO, R. Multiple herbicide resistance Evolution: the case of Eleusine indica in Brazil. Journal of Agricultural and Food Chemistry, v. 69, n. 4, p. 1197-1205, 2021. Disponível em: <http://dx.doi.org/ 10.1021/acs.jafc.0c03999>. DOI: 10.1021/acs.jafc.0c03999

VITORINO, H. S.; SILVA JÚNIOR, A. C.; GONÇALVES, C. G.; MARTINS, D. Interference of a weed community in the soybean crop in functions of sowing spacing. Revista Ciência Agronômica, v. 48, n. 4, p. 605-613, 2017. Disponível em: <http://dx.doi.org/10.5935/1806-6690.20170070>. DOI:10.5935/1806-6690.20170070

WEEDSCIENCE. Herbicide resistant goosegrass globally (Eleusine indica). Disponível em: <http://weedscience.org/Pages/Species.aspx>. Acesso em 05 de junho de 2021. 